\title{
Variable Performance of Evidence-Based Guidelines for Echocardiography in Patients with Hip Fractures
}

Eric Swart MD', Chris Adair MD², Rachel Seymour PhD², Madhav Karunakar MD2

${ }^{1}$ Department of Orthopaedic Surgery, University of Massachusetts, Worcester, Massachusetts

${ }^{2}$ Department of Orthopaedic Surgery, Atrium Health Musculoskeletal Institute, Charlotte, North Carolina;

\section{Purpose}

- Osteoporotic hip fractures common in medically frail patients

- Clinical practice guidelines (CPGs) exist to help determine when pre-operative trans-thoracic echocardiography (TTE) is indicated

- Unclear which guidelines perform the best in patients with hip fractures

\section{Methods}

- Retrospective chart review

- 100 patients who underwent pre-operative TTE prior to hip fracture fixation

- Data extracted: History, physical exam, listed indications for TTE, actual TTE findings

- Five accepted CPGs compared:

-American College of Cardiology $(\mathrm{ACC} / \mathrm{AHH})$

-British Society of Echocardiography (BSE)

-European Society of Echocardiography (ESC/ESE)

-Association of Anesthesia of Great Britain and Ireland (AAGBI)

-Scottish Intercollegiate Guidelines Network (SIGN)

\section{Results}

- Patients met criteria for TTE $32-66 \%$ of the time, based on the CPG used

- TTE revealed new information with potential to alter peri-operative management $14 \%$ of the time

- $\mathrm{ACC} / \mathrm{AHH}$ and SIGN guidelines had the best performance

-Focused on change in clinical status

\section{Table 1 - Medical Comorbidities}

\begin{tabular}{|l|c|}
\hline Documented Comorbidity on Presentation & Prevalence \\
\hline Hypertension & $62 \%$ \\
\hline Congestive Heart Failure & $42 \%$ \\
\hline Hyperlipidemia & $29 \%$ \\
\hline Diabetes Mellitus & $27 \%$ \\
\hline Osteoporosis & $24 \%$ \\
\hline History of Cancer & $22 \%$ \\
\hline Depression & $22 \%$ \\
\hline Chronic Obstructive Pulmonary Disease & $21 \%$ \\
\hline Cerebrovascular Accident & $19 \%$ \\
\hline Gastro-Esophageal Reflux Disease & $17 \%$ \\
\hline End Stage Renal Disease & $4 \%$ \\
\hline History of previous fragility fracture & $4 \%$ \\
\hline Hemodialysis & $3 \%$ \\
\hline
\end{tabular}

Table 2 - Performance of CPGs

\begin{tabular}{|c|c|c|c|c|c|}
\hline Guideline & ACC/AHH & BSE & ESC/ESE & AAGBI & SIGN \\
\hline $\begin{array}{l}\text { \% TTEs in } \\
\text { accordance with } \\
\text { guidelines }\end{array}$ & $66 \%$ & $65 \%$ & $32 \%$ & $50 \%$ & $66 \%$ \\
\hline Sensitivity & $100 \%$ & $79 \%$ & $71 \%$ & $71 \%$ & $100 \%$ \\
\hline Specificity & $40 \%$ & $37 \%$ & $74 \%$ & $54 \%$ & $40 \%$ \\
\hline $\begin{array}{l}\text { Reduction in } \\
\mathrm{TTE}^{1}\end{array}$ & $34 \%$ & $35 \%$ & $68 \%$ & $50 \%$ & $34 \%$ \\
\hline $\begin{array}{c}\text { Missed } \\
\text { Pathology }\end{array}$ & $0 \%$ & $12 \%$ & $3 \%$ & $4 \%$ & $0 \%$ \\
\hline
\end{tabular}

\section{Discussion}

- TTE can be useful for identifying pathology in hip fracture patients that can alter peri-operative management

- CPGs can be used to safely identify which patients could benefit from TTE 